\title{
The effect of self-regulated learning on academic achievement of secondary school physics students
}

\author{
Achufusi-Aka $^{5}$ N. N. \& Offiah $^{6}$ F. C.
}

\begin{abstract}
This study ascertained the effect of self-regulated learning on students' academic achievement in physics. It is a quasi-experimental design in which two co-educational schools were used and randomly assigned as experimental and control groups .Two research questions and one hypothesis guided the study. The instrument was a physics achievement test designed by the researcher .The study was carried out in Onitsha education zone of Nigeria with a population of 12,104 science students. A sample of 60 students from two co-educational schools were used for the study, Analysis of result using t-test showed that self-regulated learning students performed significantly better than the non-self regulated learning counterparts.

Keywords self-regulated learning, academic achievement in physics, learning physics
\end{abstract}

\section{Introduction}

The development of early science education is to enable learners acquire scientific ideals at the early stage of life .Emphasis in Nigeria and the world today is on development of science and its implications. Considerable research has focused on the investigation of the ways in which motivational and cognitive components of academic learning work together . The learning environment is usually an essential factor in any learning situation. The learning environment comprises teacher's teaching strategies; classroom activities; student-teacher and student-student interactions that would influence an individual's motivation in learning (Pintrich and Schunk, 1996). If the students' goal towards task is for performance, they will be concerned with performing better than their peers and impressing their teachers (Pintrich and Schunk, 1996). The learning motivation studies revealed a variety of motivational factors such as self-perceptions of ability, self-efficacy; self-regulated learning; task orientation and learning strategies (Garcia and Pintrich, 1995). The academic self-regulation is a degree to which students are motivationally, meta-cognitively and behaviorally active in their learning process and in accomplishing their goals (Zimmerman, 2000). It is clear that students are active participants of their own learning. Indeed self-regulation involves monitoring, management and control of cognition; motivational behavior and environment in order to achieve set goals (Pintrich, 2003).

\footnotetext{
${ }^{5}$ Achufusi-Aka N. N. lectures at the Department of Science Education, Nnamdi Azikiwe University, P.M.B. 5025, Awka, Anambra State, Nigeria

${ }^{6}$ Offiah Francisca C., also lectures at the Department of Science Education, Nnamdi Azikiwe University, P.M.B. 5025, Awka, Anambra State, Nigeria
} 
The students monitor and control their learning by using different strategies and managing their time and study environment effectively. The self-regulated learners have high motivation to use cognitive and meta-cognitive strategies to regulate their cognition and effort. Indeed (Pintrich and Zusho, 2003) suggested that if students have no motivation to use various meta-cognitive strategies, possessing knowledge on these will not be sufficient for them to learn effectively.

Pintrich (2000) synthesized the work of a variety of self-regulatory learning theories into a general frame work and proposed the phase as:

(a) Fore thought or planning

(b) Monitoring

(c) Control

(d) Reaction and Reflection.

The fore thought concerns students goal setting and planning; Perceptions of task value and prior knowledge motivation in relation to task monitoring phase involves processes whereby students are meta-cognitively aware of self, task or context and self-observe their behavior. Control Phase concerns reflection and use of appropriate strategies for learning, motivation and effect. The students may enhance or diminish their effort depending on task demands. The reaction phase involves affective reactions, cognitive judgment choice behaviors and task evaluation (Pintrich, 2004). Black-burn (2000), in a study on self-Regulated Learning Assessment system for Engineering technology Students found that Self-Regulated learners on the Electric Circuits had lower attrition rates and higher grades than the Control Section. Hoym(2004) in a study on A Comprehensive Cognitive Skills Academy (ACCSA) for degree students found that $84 \%$ of self-regulated learning students passed the tests, Also Self-Regulated learning students (SRL) earned statistically higher grades in a college-level mathematics than the non-SRL students.

Physics is one of the science subjects that records low enrolment and performance in WAEC exams over the years (WAEC, 2003, 2005). Many factors such poor teaching methods students factor and lack of interest are responsible for this effect. The importance of efficient and effective teaching of science was buttressed by Oriafor (1990) in the sense that the interest and mastery students demonstrate on completion of a course of study depended on the teaching method and teaching strategies used. This situation therefore calls for exploration of the effectiveness of Self-Regulated learning model (SRLM) which has been found effective in some subjects. Hence this study will be faced with the problem of evaluating SRL as an Instructional model in influencing achievement in Physics.

\section{Purpose of study and research questions}

This study was intended to determine the effect of self-Regulated learning on the academic achievement of physics. The study attempted to provide evidence of the benefits of Self regulated learning in enhancing students' achievement in physics. The following questions guided the study:

1. What is the effect of self-regulated learning on students' achievement in physics?

2. To what extent does gender affect self-regulated learning of students on physics? 
In order to explore these questions, the following hypothesis was formulated: "there is no significant different in the academic achievement between students exposed to motivational self-regulated learning in physics lessons and their counterparts not so exposed to".

\section{Methodology}

Design: This study is a quasi-experimental study and employed a pre-test, post-test nonrandomized control group design.

Population and sample: The study was carried out in Onitsha education zone of Nigeria which consists of thirty-two secondary schools, 827 teachers and 12,056 students. The choice of Onitsha is that Onitsha has enough co-educational schools for the study. A stratified random sampling was done to select two co-educational schools in Onitsha North. The sample consisted of sixty-six students from two intact classes, which were randomly assigned experimental and control groups.

Instrument: The instrument consists of Physics Achievement Test (PAT) developed by the researchers. It consists of 30 multiple choice items. The reliability of the instrument was done using Kuder-Richardson 20 formula and a value of 0.77 was recorded. The validity of the instrument was done by giving the PAT to three physics lecturers and 2 research persons to ascertain for clarity of words and face content validation.

Method of data collection and analysis: Six teacher trainees were selected from the schools and were trained for two weeks. At the end of the period, only three teachers were selected and helped the researchers administer the treatment. Before treatment, both groups were given a pre-test, the experimental group had their learning on motion and energy regulated according to the phases specified by Pintrich (2004) while the control group was taught motion and energy using a lesson plan by their teacher. The treatment exercise lasted for three weeks after which both groups were given a Post-test (reshuffled Pre-test). The raw scores for both Pre-test and Post-test were collected and analyzed using t-test.

\section{Results}

\section{The effect of self-regulated learning on students' achievement in physics}

As indicated above, the major purpose of the study was to determine the effect of selfregulated learning on the academic achievement of physics. Table 1 shows the results of the pre-test of experimental and control groups.

Table 1 Summary of t-test analysis for the pre-test of experimental and control groups

\begin{tabular}{llllllll}
\hline Variables & $\begin{array}{l}\text { No. of } \\
\text { Students }\end{array}$ & Mean & $\begin{array}{l}\text { Standard } \\
\text { deviation }\end{array}$ & $\propto$ & d.f. & t-cal & c-rit \\
\hline Experimental & 50 & 34.64 & 7.06 & 0.05 & 98 & 0.544 & 1.960 \\
Control & 50 & 33.96 & 5.47 & & & & \\
\hline
\end{tabular}

Table 1 shows that there was no significant difference between the control and experimental group before the treatment. The two groups were at same equivalence level in terms of academic achievement in physics.

The results from the post test were also subjected to a t-test to test the null hypothesis that "there is no significant different in the academic achievement between students exposed 
to motivational self-regulated learning in physics lessons and their counterparts not so exposed to". Table 2 shows the results of the t-test analysis for the post-test of experimental and control groups

Table 2 Summary of t-test analysis for the post-test of experimental and control groups

\begin{tabular}{llllllll}
\hline Variables & $\begin{array}{l}\text { No. of } \\
\text { Students }\end{array}$ & Mean & $\begin{array}{l}\text { Standard } \\
\text { deviation }\end{array}$ & $\propto$ & d.f. & t-cal & c-rit \\
\hline Experimental & 50 & 79.52 & 11.55 & 0.05 & 98 & 7.66 & 1.96 \\
Control & 50 & 62.28 & 11.06 & & & & \\
\hline
\end{tabular}

In Table 2, a significant difference can be observed between the experimental and control groups after the treatment $(\propto<0.005)$. This shows that experimental group with mean and standard deviation 79.52 and 11.55 respectively, performed significantly better than the control group with mean and standard deviation 62.28 and 11.06 respectively. The major explanation for this the experimental group was subjected to motivational self-regulated learning.

\section{Discussion of Results/Recommendations}

The result of this study shows that there was a significant difference in the academic achievement of students exposed to academic self-regulation and the students taught with lecture method. There was a difference only after the treatment ie. Academic SelfRegulation. This agrees with the views of Zimmerman (2000); who stated that selfregulated learners have high motivation to use cognitive and meta-cognitive strategies to regulate their cognition and effort. It also agrees with studies of Pintrich (2003); Capara and Pastorelli (1996), that Self-Regulated learners tended to put greater effort to succeed on a task, do not give up easily in the face of difficulties and use meaningful learning Strategies and show intrinsic interest in their academic work.

\section{Conclusion and Recommendations}

It can be argued from the above results that exposing students to academic self-regulation learning can improve the performance of students. Based on this conclusion, the following recommendations are made

- The educational planner should utilize the results of this experimental study to fashion out appropriate teaching methods for teachers in our educational system.

- Physics teachers should be encouraged and supported to develop their students' selfregulation learning skills so as to empower them to analyze, interpret, predict information and regulate their learning.

- In-service training, seminars and workshops which will expose secondary school science teachers to such innovations should be organised regularly.

\section{References:}

Ames C \& Archer J (1998). Achievement goals in the Classroom. Student Learning Strategies and Motivation Processes. Journal of Educational Psychology 80,260267. 
African Journal of Educational Studies in Mathematics and Sciences Vol. 8, 2010

Black-burn M. (2000).Academic Learning, Unpublished doctoral dissertation, University of Oaklahoma.

Hoy A.W. (2004). What do teachers know about self-efficacy? The paper presented at the Annual General Meeting of the American Educational Research San DiegoU.S.A.

Pintrich P.R.(2003).A Conceptual framework for asses of information ,motivation and self-regulated learning in college students Educational Psychology Review 16, $385-407$

Pintrich P.R.and Schunk D.H. (2002).Motivation in education: Theory; research and applications, Columbus $\mathrm{OH}$ : Merrill

Schunk D.H. \& Pajares F (2001).The Development of Self-Efficacy, Development of Achievement Motivation. San Diego, Academic Press.

Sungar S \& Tekays .C (2006).Effects of problem based Learning and traditional institution on self-regulated learning. The Journal of Educational Research, 99,307-317. 
